\title{
Effect of two Different Types of Surface Sealants on Micro-Leakage of Class V Composite Restoration
}

\author{
Nazish Fatima, Sidra Mohiuddin
}

\begin{abstract}
OBJECTIVE: To determine the effect of filled and unfilled sealants on micro-leakage of class $V$ composite restoration.

METHODOLOGY: This in-vitro experimental study was performed at department of dental materials from August 2018 to January 2019. Sample selection was performed through non probability convenience sampling. Class V cavities were prepared on the buccal surfaces of sixty extracted teeth at the level of cemento-enamel junction (CEJ), the coronal margins were facing towards enamel and gingival margins were at dentine. Later, cavities were filled with an adhesive system and composite, followed by polishing. Samples were randomly divided in to 3 groups according to surface sealants. Twenty teeth in each group (Clinpro, GC coat and Control) and preserved in the incubator at $37^{\circ} \mathrm{C}$ with in airtight containers that were filled with $10 \mathrm{ml}(5 \%)$ solution of Methylene blue dye. After 24 hours samples were dissected longitudinally in bucco-lingual direction and evaluated under a stereo microscope. The data were statistically analyzed by chi square test.

RESULTS: Association among all 3 groups at gingival level was found to be statistically significant with $p$ value of 0.001 and chi square value of 30.46 . Furthermore, at coronal level micro leakage was found to be statistically insignificant with $p$ value of 0.619 and chi square value of 2.64 .

CONCLUSION: Both surface sealants have shown effectiveness in reduction of micro-leakage. However, Clinpro has presented with better reduction in micro-leakage than GC coat.
\end{abstract}

KEYWORDS: Sealants, Micro-leakage, dye penetration, class $V$ restoration.

This article may be cited as: Fatima N, Mohiuddin S. Effect of two Different Types of Surface Sealants on Micro -Leakage of Class V Composite Restoration. J Liaquat Uni Med Health Sci. 2019;18(04):295-300. doi: 10.22442/jlumhs. 191840646

\section{INTRODUCTION}

Nowadays, development in adhesive technology results in increased use of composite resin. It represents distinctive class of restorative material with recent advancements it has replaced biological tissue in both the appearance and function. Regardless of this development; still micro-leakage is the single leading cause of the restoration failure. Thus this limitation has reduced life span of the restoration hence results in the initiation for the development of new techniques as along with materials ${ }^{1}$. However, literature had reported different techniques that can be used to overcome the limitation for reducing micro-leakage within the restotation ${ }^{2-8}$.

Recently after the invention of the new material named as a restorative covering agent or surface sealant; that is considered as the solution for restoration failure due to micro-leakage ${ }^{9}$. Hence, surface sealants are found as polymerizable materials consisting of unfilled resins and low molecular weight monomers along with photo initiators and other modifiers. ${ }^{1}$ Furthermore, it has been evidenced that to improve the mechanical properties of the surface sealants, filler particles are also incorporated to its composition $^{1,9}$.

Application of surface sealants over the cavosurface margins of the restorations helps in filling up structural micro-defects created during finishing and polishing procedures via capillary action mechanism. This application will also reduce the micro-leakage by improving the marginal seal of the restoration.

Recently it has been reported that low viscosity, high flow rate and wettability; are important properties that helps in the penetration (fluidity) onto restoration subsurface microstructure resulting in better clinical performance of surface sealants ${ }^{10}$. On the contrary, surface sealants which have low-viscosity are highly subjected to abrasion thus to overcome this physical wear problem; surface sealants with filler and/or conventional pits and fissure sealants are suggested to be used.

Moreover, some studies have also claimed that sealant viscosity due to presence of fillers may adversely affect the success of surface sealant as these studies have reported that low viscosity sealant material exhibit better marginal adaptation that facilitate reduction in microleakage ${ }^{11-15}$, but other studies have also reported that there was no 
difference between unfilled and filled sealants regarding micro-leakage scores ${ }^{16}$.

Hence as a result of mixed literature reviews, there is a need for further studies in order to evaluate new materials that will help in ensuring the reduction of micro-leakage thus allowing clinicians to use these materials during routine restorative procedures. Therefore, the objective of current study was to compare the effect between filled and unfilled sealant on micro leakage of Class $\mathrm{V}$ composite restoration.

\section{METHODOLOGY}

This in vitro experimental study was conducted at the Department of Science of Dental Materials from August 2018 to January 2019.Total sample size of $\mathrm{n}=60$ extracted permanent human premolar teeth were used through non probability convenience sampling. All extracted teeth were taken from the department of Oral and Maxillofacial Surgery of the same Private Teaching Dental Hospital, verbal consent was taken from patient before extraction.

Human permanent premolar with intact buccal enamel surface without any lesion and pre-treatment extracted for orthodontic reasons were included. Teeth with fractured crowns, chipped enamel, caries and restoration were excluded.

Hard and soft deposits were cleaned mechanically and later were kept in thymol solution for no longer than seven days. Standards of ISO/TS 11405 were monitored for handling and storage of extracted teeth.

Class $V$ cavity was prepared by using \#330 carbide bur with the help of high-speed hand piece, cooled with an air-water spray on the buccal surfaces of all the teeth at the level of cemento-enamel junction (CEJ), with the coronal margins of the cavity was located at enamel and the gingival margins located at dentin. The size of cavity was $3.0 \mathrm{~mm} \times 3.0 \mathrm{~mm} \times 1.5$ $\mathrm{mm}$; periodontal probe was used to check uniformity of the size. All preparation surfaces were conditioned for $15 \mathrm{sec}$ with $37 \%$ phosphoric acid. Later, the cavity were washed gently for 20 seconds and dried with air. Further, after drying the cavity, according to manufacturers' instructions adhesive system Prime \& Bond Elect (Dentsply Caulk, Milford, DE, USA) was applied. Followed by Filtek Z350 composite resin (3M ESPE, USA) was filled in the cavities by incremental technique. The thickness of the material was kept $1 \mathrm{~mm}$ and placed in form of layers. After placement of the composite resin, the thickness of the layers were checked by using periodontal probe followed by use of light curing technique for $20 \mathrm{sec}$. These samples were kept in artificial saliva for 24 hours at $37 \mathrm{C}$ before polishing. Every restoration was polished (NSK Ti-Max Electric Hand piece, Japan) according to manufacturer instructions in a rounded manner with light pressure.
All procedures were performed by single operator at $32^{\circ} \mathrm{C}$.

After preparations all the samples were randomly distributed in to 3 groups with 20 teeth in each group.

\section{Group I (Clinpro)}

The complete surface of the restoration with 1-2 $\mathrm{mm}$ beyond the tooth/restoration margin was etched with phosphoric acid for $20 \mathrm{sec}$ followed by rinsing with water and drying. A thin layer of Clinpro was applied to the restoration/tooth surfaces and light cure for 20 sec.

\section{Group II (GC Coat Plus)}

Single G-Coat was applied to the restoration, restoration/tooth surfaces and light cured for $20 \mathrm{sec}$.

\section{Group III (Control)}

Control group did not receive any kind of surface protection. Moreover, the nail varnish (two layers) was applied to all the tooth surfaces up till $1 \mathrm{~mm}$ short of the restoration margins along with utility wax that was used to seal root apices for creation of vacuum. These specimens were stored in the incubator at $37^{\circ} \mathrm{C}$ by storing them in an airtight container containing $10 \mathrm{ml}$ of $5 \%$ solution of Methylene blue dye (MERCK). Twenty four hours later samples were cleaned with water and dried. Nail varnish was scrapped off by using scalpel.

Then teeth were then dissected longitudinally in bucco -lingual direction from the center of restoration by using diamond disk in a digital low speed cutting saw (MTI Corp. USA) under water spray. Finally the teeth were observed under a stereomicroscope (Motic DMW-143-FBGC Hong Kong) at $20 \mathrm{x}$ for dye penetration at occlusal and gingival margins, results were classified as follows: $0=$ No dye penetration, I= Dye penetration up to less than half the cavity depth, II= Dye penetration more than half the cavity depth without axial wall involvement, III= Dye penetration up to the axial wall or traversing the axial wall.

Statistical analysis was performed by using SPSS version 18. Quantitative variables were reported as means and standard deviation, qualitative were reported as frequencies and percentages. Association among the variables was find out by using chi square test. Level of significance was kept at $p=0.05$

\section{RESULTS}

A total sample size of $n=60$ observations were made for micro leakages at coronal as well as gingival levels. For 60 coronal micro leakage observations, $91.7 \%(n=55)$ observations were those in which there was no dye penetration, $6.7 \%(n=04)$ and $1.7 \%(n=01)$ were with slight and moderate dye penetration respectively. Furthermore, for 60 gingival micro leakage observations, $33.3 \% \quad(n=20)$ observations were found to have no dye penetration, however $45 \%$ 
$(n=27), 3.3 \%(n=02)$ and $18.3 \%(n=11)$ were recorded with slight, moderate and severe dye penetration respectively.(Table I and Figure I)

TABLE I:

DESCRIPTIVE ANALYSIS OF MICRO LEAKAGE

\begin{tabular}{|l|c|c|}
\hline \multicolumn{1}{|l|}{ Variable } & $\begin{array}{c}\text { Frequency } \\
\mathbf{n = 6 0}\end{array}$ & $\begin{array}{c}\text { Percentage } \\
\text { (\%) }\end{array}$ \\
\hline Coronal Micro leakage \\
\hline No dye penetration & 55 & 91.7 \\
\hline Slight dye penetration & 04 & 6.7 \\
\hline Moderate dye penetration & 01 & 1.7 \\
\hline \multicolumn{3}{|l|}{ Gingival Micro leakage } \\
\hline No dye penetration & 20 & 33.3 \\
\hline Slight dye penetration & 27 & 45 \\
\hline Moderate dye penetration & 02 & 3.3 \\
\hline Severe dye penetration & 11 & 18.3 \\
\hline
\end{tabular}

FIGURE I: ASSOCIATION AMONG GINGIVAL MICRO LEAKAGE \& SEALANTS

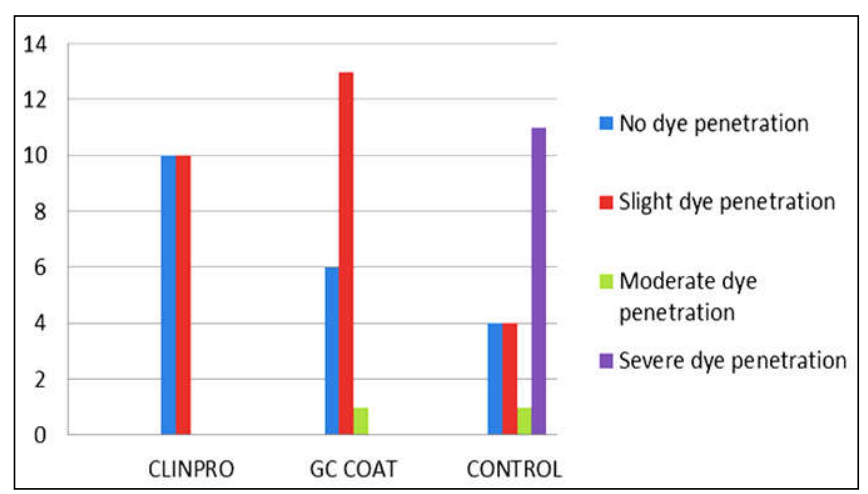

The raw percentage for sealant 1 (CLINPRO) were found to be $50 \%$ for no dye penetration and $50 \%$ for slight dye penetration with gingival micro leakage. Furthermore, with sealant 2 (GCCOAT) the raw percentages were $65 \%$ with slight dye penetration, $30 \%$ with no dye penetration and $05 \%$ with moderate dye penetration. The raw percentages with control group (NO SEALANT) were found as $20 \%$ for no and moderate dye penetration, $11 \%$ for severe and $5 \%$ for moderate dye penetration. Association among all 03 groups gingival micro leakage was found to be statistically significant with the $p$ value of 0.000 and chi square value of 30.46. (Table II and Figure II)

\section{FIGURE II: ASSOCIATION AMONG CORONAL \&} MICRO LEAKAGE AND SEALANTS

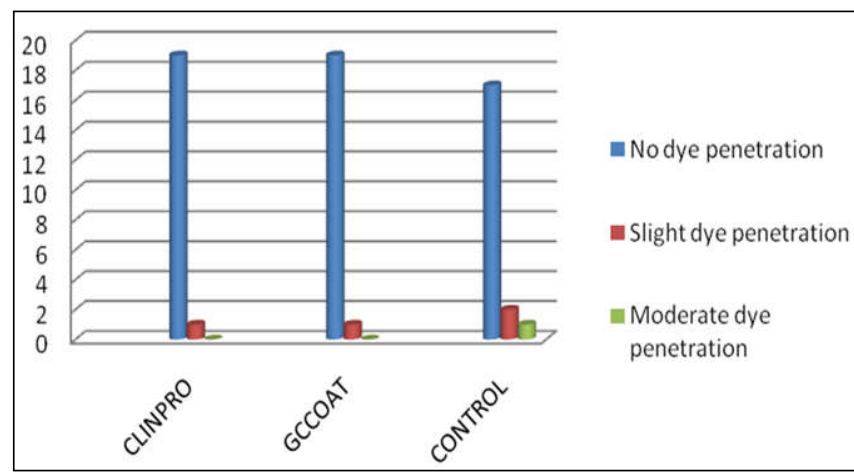

Raw percentages for sealant 1 (CLINPRO) were found to be $95 \%$ for no dye penetration and $5 \%$ for slight dye penetration with coronal micro leakage. Furthermore, with sealant 2 (GCCOAT) the raw percentages were $95 \%$ with no dye penetration, $5 \%$ with slight dye penetration. The raw percentages of control group (NO SEALANT) were found as $85 \%$ with no dye penetration, $10 \%$ with slight and $5 \%$ with

TABLE II: ASSOCIATION AMONG GINGIVAL MICRO LEAKAGE \& SEALANTS

\begin{tabular}{|c|c|c|c|c|c|c|}
\hline Variable & \multicolumn{4}{|c|}{ Gingival Micro leakage } & \multirow{2}{*}{$\begin{array}{c}\text { Pearson chi } \\
\text { square }\end{array}$} & \multirow[b]{2}{*}{ p-value } \\
\hline Sealants & $\begin{array}{c}\text { No dye } \\
\text { penetration }\end{array}$ & $\begin{array}{l}\text { Slight dye pene- } \\
\text { tration }\end{array}$ & $\begin{array}{l}\text { Moderate dye } \\
\text { penetration }\end{array}$ & $\begin{array}{l}\text { Severe dye } \\
\text { penetration }\end{array}$ & & \\
\hline CLINPRO & $10(50 \%)$ & $10(50 \%)$ & $0(0 \%)$ & $0(0 \%)$ & \multirow{3}{*}{30.46} & \multirow{3}{*}{$0.000^{*}$} \\
\hline GC COAT & $06(30 \%)$ & $13(65 \%)$ & $01(5.0 \%)$ & $0(0 \%)$ & & \\
\hline CONTROL & $04(20 \%)$ & $04(20 \%)$ & $01(5.0 \%)$ & $11(55 \%)$ & & \\
\hline
\end{tabular}

Chi square test for association, *statistically significant

TABLE III: ASSOCIATION AMONG CORONAL \& MICRO LEAKAGE AND SEALANTS

\begin{tabular}{|c|c|c|c|c|c|}
\hline Variable & \multicolumn{3}{|c|}{ Coronal micro leakage } & \multirow{2}{*}{$\begin{array}{l}\text { Pearson chi } \\
\text { square }\end{array}$} & \multirow{2}{*}{ p-value } \\
\hline Sealants & No dye penetration & Slight dye penetration & Moderate dye penetration & & \\
\hline CLINPRO & $19(95 \%)$ & $01(05 \%)$ & $0(0 \%)$ & \multirow{3}{*}{2.64} & \multirow{3}{*}{$0.61^{*}$} \\
\hline GCCOAT & $19(95 \%)$ & $01(5 \%)$ & $0(0 \%)$ & & \\
\hline CONTROL & $17(85 \%)$ & $02(10 \%)$ & $01(05 \%)$ & & \\
\hline
\end{tabular}

Chi square test, *statistically insignificant 
moderate dye penetration respectively. Association among all 03 groups coronal micro leakage was found to be statistically insignificant with the $p$ value of 0.619 and chi square value of 2.64.(Table III)

\section{DISCUSSION}

In current study we found that there was a significant difference among two sealants (Clinpro and GC coat) in terms of gingival micro-leakage. However, Clinpro was found to be better in reduction of gingival micro-leakage. On the contrary there was insignificant difference in Clinpro and GC coat at coronal level.

As one of the main reasons for the failure of restoration's in restorative dentistry is micro-leakage that is due to the destruction of marginal adaptation of restoration with tooth surface, therefore an ideal marginal seal is an important factor for the long life of the restoration ${ }^{17}$. A study concluded that surface sealant can close the micro-leakage on the margin of the composite resin restoration resulted in better cavity after finishing and polishing than a bonding agent ${ }^{18}$.

Thus for evaluating the sealing ability of the material different micro-leakage test methods were applied ${ }^{19-22}$. Of which the method of dye penetration was commonly in used because of the ease in application along with consistency of results ${ }^{20,23}$. Among two different types of composite surface sealants that is filled (Clinpro) and unfilled (GC coat), literature have suggested that unfilled sealants were less viscous therefore they penetrate deeply into micro gaps as well into surface micro-defects but due to lack of filler particles they were found to be more prone to abrasion $^{24-26}$.

On the other hand, although Clinpro was traditionally used as pits and fissure sealants however, when we had used it as surface sealants in current study it gave better results at gingival level than GC coat but almost similar results at coronal level. Furthermore because of the presence of filler particles in sealant they have resulted in minimal abrasion of the material resulting in the longitivity of the restoration. Similarly literature reported that unfilled or nano-filled surface sealants were the most effective in decreasing the degree of marginal micro-leakage at coronal margins ${ }^{27-30}$.

One of our findings from current study that was better abrasion resistance of surface sealant was the important factor for long life of restoration was in accordance with the study performed by Kawai K and Leinfelder KF $1993^{31}$. They have also reported that the unfilled surface sealant was slightly resistant to abrasion or wear; hence, the sealant that only penetrates into the restoration can increases the resistance to wear therefore, there is the need for sealants that have improved abrasion resistance.
Similarly Davari A $2012^{32}$ concluded that filled and unfilled sealant materials had presented with different rates of effectiveness moreover, filled sealants had reported to decrease marginal micro-leakage significantly as it showed more wear resistance. In current study we have found that filled surface sealants had given better results in reduction of micro-leakage at gingival level but similar results with that of unfilled surface sealants at coronal level. This outcome was in contrary with study by dos Santos PH et al. ${ }^{33}$ In which he they had assessed the effects of surface sealants and dentin adhesive systems on micro-leakage and found that unfilled sealants presented lower micro-leakage values than filled surface sealants. Difference may be due to change in use of storage media as well as time duration for storage of samples.

The reason Clinpro has produced improved result was the same composition of resin in both Clinpro (sealants) and composite restoration that made good compatibility and stronger bond between them.

\section{CONCLUSION}

The conclusions drawn from the current study were that Surface sealant (filled \&unfilled) had shown effective reduction in micro-leakage at gingival and coronal level as compare to control group and Clinpro (filled) sealants had better reduction in micro-leakage at gingival level however; resulted in similar reduction of micro-leakage at coronal level when compare with GC coat (unfilled) surface sealants.

Ethical permission: College of Dentistry, Ziauddin University, Karachi; Letter No ZCD 1167 Dated: 28-03 $-2019$

Conflict of interest: Authors of the study have no conflict of interest to declare.

Funding: No funding resources, Self-funded

\section{REFERENCES}

1. Sadeghi M, Davari A, Lynch CD. The effect of re-bonding using surface sealant or adhesive system on microleakage of class $V$ resin composite restorations. Dent Res J (Isfahan) 2013;10(5): 596-601.

2. Ozsoy A, Eren MM, Gurbuz O, Dikmen B, Cilingir $A$, Erdemir U. Effect of desensitizers on the microleakage of previously restored Class $\mathrm{V}$ resin composite restorations. J Adhes Sci Technol. 2016; 30(20): 2201-11. doi:10.1080/ 01694243.2016.1177319.

3. Magni E, Zhang L, Hickel R, Bossù M, Polimeni A, Ferrari M. SEM and microleakage evaluation of the marginal integrity of two types of class $\mathrm{V}$ restorations with or without the use of a 
light-curable coating material and of polishing. J Dent. 2008; 36(11): 885-91. doi: 10.1016/j.jdent. 2008.07.003.

4. Atoui JA, Chinelatti MA, Palma-Dibb RG, Corona SA. Microleakage in conservative cavities varying the preparation method and surface treatment. $\mathrm{J}$ Appl Oral Sci. 2010;18(4): 421-5. doi: 10.1590/ S1678-77572010000400017

5. Ghavamnasiri M, Moosavi $\mathrm{H}$, Tahvildarnejad N. Effect of centripetal and incremental methods in Class II composite resin restorations on gingival microleakage. J Contemp Dent Pract. 2007; 8 (2):113-20.

6. Hepdeniz OK, Temel UB, Ugurlu M, Koskan $O$. The effect of surface sealants with different filler content on microleakage of Class $V$ resin composite restorations. Eur. J. Dent. 2016;10 (2):163-9.doi:10.4103/1305-7456.178315.

7. Gupta SK, Saxena P, Pant VA, Pant AB. Release and toxicity of dental resin composite. Toxicol Int. 2012;19(3):225-34. doi: 10.4103/0971-6580. 103652.

8. Demirci M, Tuncer S, Tekce N, Erdilek D, Uysal $O$. Influence of adhesive application methods and rebonding agent application on sealing effectiveness of all-in-one self-etching adhesives. J Esthet Restor Dent. 2013; 25(5): 326 -43. doi: 10.1111/jerd.12034.

9. Lopes MB, Saquy PC, Moura SK, Wang L, Graciano FM, Correr Sobrinho L, et al. Effect of different surface penetrating sealants on the roughness of a nanofiller composite resin. Braz Dent J. 2012; 23(6): 692-7.

10. Lokhande NA, Padmai AS, Rathore VP, Shingane $S$, Jayashankar DN, Sharma U. Effectiveness of flowable resin composite in reducing microleakage - An in Vitro study. J Int Oral Health. 2014; 6 (3): 111-4.

11. Yamada $Y$, Hossain $M$, Shimizu $Y$, Kimura $Y$, Masuda $Y$, Nakamura $Y$, et al. Analysis of surface roughness and microleakage of fissure sealants following organic debris removal with Carisolv. J Dent. 2008; 36(2): 130-7. doi: 10.1016/j.jdent. 2007.11.009.

12. Dukic W, Dukic OL, Milardovic S. The influence of Healozone on microleakage and fissure penetration of different sealing materials. Coll Antropol. 2009; 33(1): 157-62.

13. Oliveira BLS, Costa, AR, Correr AB, Crepaldi MV, Correr-Sobrinho L, Santos JCB. Influence of adhesive and bonding material on the bond strength of bracket to bovine tooth. Braz J Oral Sci. 2017; 16(3):1-7. doi:10.20396/bjos.v16i0.8650493.

14. Kantovitz KR, Moreira KM, Pascon FM, Nociti FH Jr, Machado Tabchoury CP, Puppin-Rontani RM.
Penetration of filled and unfilled resin sealants on different enamel substrates. Pediatr. Dent. 2016; 38(7): 472-6.

15. Jager S, Balthazard R, Dahoun A, Mortier E. Filler Content, Surface Microhardness, and Rheological Properties of Various Flowable Resin Composites. Oper Dent. 2016;41(6):655-65.

16. Mehrabkhani M, Mazhari F, Sadeghi S, Ebrahimi M. Effects of sealant, viscosity, and bonding agents on microleakage of fissure sealants: An in vitro study. Eur J Dent. 2015; 9(4): 558-63. doi: 10.4103/1305-7456.172631.

17. Arora R, Kapur R, Sibal N, Juneja S. Evaluation of Microleakage in class II cavities using packable composite restorations with and without use of liners. Int J Clin Pediatr Dent. 2012; 5: 178-84. doi: 10.5005/jp-journals-10005-1162.

18. Mariani A, Sutrisno G, Usman M. Marginal microleakage of composite resin restorations with surface sealant and bonding agent application after finishing and polishing. J Physics Conf Series. 2018; 1073(4): 042005.

19. Celik C, Cehreli SB, Arhun N. Resin composite repair: Quantitative microleakage evaluation of resin-resin and resin-tooth interfaces with different surface treatments. Eur J Dent. 2015; 9(1): 92-99. doi: 10.4103/1305-7456.149652.

20. Idriss S, Abduljabbar T, Habib C, Omar R. Factors associated with microleakage in Class II resin composite restorations. Oper Dent. 2007; 32(1): 60-66.

21. Ernst CP, Galler P, Willershausen B, Haller B. Marginal integrity of class $V$ restorations: SEM versus dye penetration. Dent Mater. 2008; 24(3): 319-27.

22. Heintze S, Forjanic M, Cavalleri A. Microleakage of Class II restorations with different tracers--comparison with SEM quantitative analysis. J Adhes Dent. 2008; 10: 259-67.

23. Kimyai S, Bahari M, Naser-Alavi F, Behboodi S. Effect of two different tooth bleaching techniques on microhardness of giomer. $J$ Clin Exp Dent. 2017; 9(2): e249-e253.

24. Owens BM, Johnson WW. Effect of new generation surface sealants on the marginal permeability of class $\mathrm{V}$ resin composite restorations. Oper Dent. 2006; 31(4): 481-8.

25. Anagnostou M, Mountouris G, Silikas N, Kletsas D, Eliades G. Chemical, mechanical and biological properties of contemporary composite surface sealers. Dent Mater. 2015; 31(12): 147486. doi: 10.1016/j.dental.2015.09.015.

26. Ruschel VC, Martins MV, Bernardon JK, Maia HP. Color match between composite resin and tooth remnant in Class IV restorations: A case series. 
Oper Dent. 2018; 43(5): 460-66. doi: 10.2341/17132-S.

27. Lima AF, Soares GP, Vasconcellos PH, Ambrosano GM, Marchi GM, Lovadino JR, et al. Effect of surface sealants on microleakage of Class II restorations after thermocycling and long-term water storage. J Adhes Dent. 2011; 13 (3): 249-54. doi: 10.3290/j.jad.a19242.

28. Ramos RP, Chinelatti MA, Chimello DT, Dibb RG. Assessing microleakage in resin composite restorations rebonded with a surface sealant and three low-viscosity resin systems. Quintessence Int. 2002; 33(6): 450-6.

29. Ramos RP, Chimello DT, Chinelatti MA, Dibb RG, Mondelli J. Effect of three surface sealants on marginal sealing of class $\mathrm{V}$ composite resin restorations. Oper Dent. 2000; 25(5): 448-53.

30. Kumar AA, Hariharavel VP, Narayanan A, Murali
S. Effect of protective coating on marginal integrity of nanohybrid composite during bleaching with carbamide peroxide: A microleakage study. Indian J Dent Res. 2015; 26(2): 167-9. doi: 10.4103/ 0970-9290.159150.

31. Kawai K, Leinfelder KF. Effect of surface-penetrating sealant on composite wear. Dent Mater 1993; 9(2): 108-113.

32. Davari A, Kazemi AD, Aboali M. Effect of two surface sealants on microleakage of class $\mathrm{V}$ resin composite restorations.J Dent Med(Tehran Univ Med Sci). 2012; 25(1): 33-40.

33. dos Santos PH, Pavan S, Assunção WG, Consani S, Correr-Sobrinho L, Sinhoreti MA. Influence of surface sealants on microleakage of composite resin restorations. J Dent Child (Chic). 2008; 75 (1): 24-8.

AUTHOR AFFILIATION:
Dr. Nazish Fatima (Corresponding author)
Assistant Professor
Science of Dental materials
Ziauddin College of Dentistry
Ziauddin University, Karachi, Sindh-Pakistan.
Email: nazishfatima654@gmail.com
Dr. Sidra Mohiuddin
Assistant Professor
Community and Preventive Dentistry
Ziauddin College of Dentistry
Ziauddin University, Karachi, Sindh-Pakistan.

